\title{
Exploring the Benefits of Using Gamification and Videogames for Physical Exercise: a Review of State of Art
}

\author{
Carina S. González-González*, Nazaret Gómez del Río, Vicente Navarro-Adelantado \\ ITED Research Group - University of La Laguna, Tenerife (Spain) \\ Received 9 January 2018 | Accepted 20 March 2018 | Published 29 March 2018
}

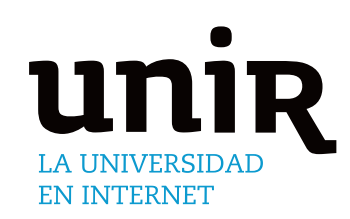

ABSTRACT

KEYWORDS

There is a lack of motivation in children and adolescents to do physical exercise and at the same time a worldwide obesity epidemic. Gamification and active videogames can be used to increase the motivation of young people, promoting healthy habits. In this work we explore different studies on active videogames, eSports and gamification applied to physical exercise and health promotion. Main findings include positive effects in a reduction in body weight and in the promotion to continue performing of physical exercise. It also contributes to increase the motivation in children and adolescents to practice exercise. The personalization of user experience and emerging technologies (big data, wearables, smart technologies, etc.) are presented as promising opportunities to keep the engagement in game-based program and gamification of physical exercise.

\author{
Physical Exercise, \\ Gamification, Active \\ Videogames, Literature \\ Review, State of The Art.
}

DOI: $10.9781 /$ ijimai.2018.03.005

\section{INTRODUCTION}

N the school or outside, physical exercise (PE) is considered a positive
element and widely as a fun, engaging and social activity. Inside
schools, there is a curricular formal PE, named Physical Education,
which main goals is to develop motor skills, knowledge and healthy
behaviors. Outside schools, PE can have many non-formal ways:
fitness, sports, dancing, etc. But, many times, the PE lessons in school
are the main PE that young people and children have [1]. Physical and
active games can attract children and young people to have a regular
PE and in this way, to promote healthy habits and wellbeing.

$\mathrm{PE}$ can be gamified or transformed into an active game if we consider that any process that satisfies the following premises can be gamified: "the activity can be learned; the user actions can be measured, and the feedbacks are timely delivered to the user" [2].

In the creation of active games, as in other types, designers must take into account fundamental elements. These game elements can be classified in many diverse ways, for example, as:

- Mechanic, story, aesthetics, and technology [3].

- Interfaces, rules, entity manipulations and goals [4].

- Mechanics, dynamics and aesthetics [5].

- Mechanics and dynamics [6].

- Dynamics, mechanics and components [7], organized in a pyramid structure, according if the element is conceptual or tactical.

Although, the most common elements associated to gamification are points, badges and leader-boards (PBL), there are diverse frameworks to design or gamify systems with a variety of elements related to the intrinsic and extrinsic motivation of user $[8,9]$. These elements allow the design of personalized gamified experiences according to the user preferences.

* Corresponding author.

E-mail address: cjgonza@ull.edu.es
In this paper we perform a literature review to extract the elements of games and gamification used for PE and their effectiveness.

\section{Studies About Games and Gamification for PE}

In the literature we can find several studies about games and PE related with the energy expenditure in educational programs carried out in schools combined with children's leisure time [10]. Main findings include that these kind of physical educative programs in schools increase the motivation of children and adolescents to continue performing physical exercise [11]. But, not all physical activity impacts in the reduction of body weight, because it depends on the frequency, duration and intensity of the activity [12]. For example, in the study carried out in [13] related to the dancing game, it was found that the cardiorespiratory answer was comparable to an aerobic dance of medium to high intensity [13].

Regarding the motivation to PE, some studies conclude that is better to encourage children participating in team rather than in individual sports [14]. Also, in other study on a group of overweight children and adolescents using an exergame (Dance Dance Revolution of Konami) as a routine physical activity, found that the game was not enough to motivate them to participate. Then, to increase participation researchers encouraged cooperative play, increased the musical variety and included a competitive mode in the activities [15]. Besides, a dancing videogame used in children's homes was evaluated while they were playing weekly in group. Results showed that the motivation and participation increased due to the group sessions [16].

Moreover, the use of active videogames has positive effects promoting an active lifestyle. A study compared the energy expenditure (EE) required by a sedentary game and two active videogames, finding that the non-active game increased $22 \%$ the EE, in contrast to active games, that increased $108 \%$ in the case of torso's movements and $172 \%$ in the case of dancing. The same study found that non-obese children had lower EE when playing the dancing video game than 
TABLE I. Gamification, Games And Physical Exercise

\begin{tabular}{|c|c|c|}
\hline Reference & Research & Major Findings \\
\hline $\begin{array}{l}{[10],[11],} \\
{[12]}\end{array}$ & $\begin{array}{l}\text { Physical activity and } \\
\text { energy expenditure } \\
\text { through educational } \\
\text { intervention } \\
\text { programs }\end{array}$ & $\begin{array}{l}\text { Positive effects in a reduction in } \\
\text { body weight and in the promotion of } \\
\text { physical exercise. }\end{array}$ \\
\hline $\begin{array}{l}{[14],[15],} \\
{[16]}\end{array}$ & Motivation & $\begin{array}{l}\text { Increasing the motivation in children } \\
\text { and adolescents to practice exercise. }\end{array}$ \\
\hline $\begin{array}{l}{[12],[13],} \\
{[14],[17],} \\
{[18],[19],} \\
{[20],[21],} \\
{[22]}\end{array}$ & $\begin{array}{l}\text { Energy expenditure } \\
\text { with active games }\end{array}$ & $\begin{array}{l}\text { Energy expenditure of an active } \\
\text { game is significantly higher than } \\
\text { that derived from other sedentary } \\
\text { activities or non-active videogames. } \\
\text { Children burned the same amount } \\
\text { of calories when they walked } \\
\text { moderately and three times more } \\
\text { than while resting (moderate } \\
\text { intensity). }\end{array}$ \\
\hline $\begin{array}{l}{[23],[24]} \\
{[25],[26]} \\
{[27],[28]}\end{array}$ & $\begin{array}{l}\text { Interactive } \\
\text { technologies to } \\
\text { promote healthy } \\
\text { habits in children }\end{array}$ & $\begin{array}{l}\text { Gaming platforms, playgrounds } \\
\text { and technologies, with gestural and } \\
\text { body movement as an interactive } \\
\text { element, promotes physical activity. } \\
\text { Also, mobile devices and wearables } \\
\text { promotes outdoor physical activity. }\end{array}$ \\
\hline $\begin{array}{l}{[29],[30],} \\
{[31],[32]}\end{array}$ & $\begin{array}{l}\text { Design of } \\
\text { active games } \\
\text { (collaboration, social } \\
\text { aspects, structural } \\
\text { elements, etc.) }\end{array}$ & $\begin{array}{l}\text { Patterns for design collaborative } \\
\text { games and structural framework } \\
\text { based on the fundamentals of } \\
\text { motor play to guide the design and } \\
\text { evaluation of active videogames. }\end{array}$ \\
\hline
\end{tabular}

obese children [17]. Other studies about EE with active games found that the EE was significantly higher in these kind of games than with conventional videogame [18], [19]. Similar findings of other study showed an increase over the base line of between $120 \%$ and $140 \%$ in the EE and the energy consumed playing active games, similar when the participant did other PE (walk, jogging, swimming) [20]. Besides, in other study the calories consumed at rest, while watching television and while walking was measured in children and compared with the calories burned when playing active videogames. The results revealed that children burned the same amount of calories when they walked moderately and three times more than while resting [21].

Although positive effects were found in several studies on the EE with active videogames, PE and sports cannot be replaced. As we mentioned above, EE depends on the intensity, duration and frequency of the activity and only a few active videogames allow performing PE with moderate intensity [22].

Several studies describe the effective use of technologies with children in the promotion of healthy habits [23]. Some gaming platforms includes body movement as an interactive element that can be used for PE [24]. Also, outdoor PE are favored by smartphones supporting different sensors tracking biometrics and allowing augmented reality activities [25]. Other technology is the Playware based on the use of sensors, actuators, hardware and software for playgrounds [26]. In Playgrounds, some game elements like social interaction, simplicity, challenge, goals, and feedback should be considered [27]. Playgrounds can be used to spatial cognitive development, considering multiple perspectives, zooming in and out, distances, experiencing movement or finding visual cues [28].

Other game elements that should be considered in the design of educative videogames in general and for active videogames in particular are collaboration and social aspects [29]. A set of theoretical elements for the design of educational videogames were proposed [30] and for monitoring and evaluating educational videogames [31].
A framework based on the fundamentals of motor play to guide the design and evaluation of active videogames have been developed [29]. Other study, analyzed the effectiveness of commercial active platform (Nintendo Wii) and an active platform designed following principles of educational, collaborative and active videogames [32]. In Table I is summarized the major findings of the literature review analyzed regarding gamification, games and physical exercise.

\section{ESPORTS AND PhysicAl EXERCISE}

Electronic sports (eSports), videogames competitions (digital sports, exergaming, cybersport, etc.) are gaining popularity around the world [33]. Perhaps, the name eSports is based on the transference of the classic classification of "sports" for electronic games that were based on a sport. Despite the eSports are officially accepted as sport in about 60 countries [34], still there is no consensus in a common definition of eSports [33]. Some authors define "eSport" as "an umbrella term used to describe organized, sanctioned video game competitions, most often in the context of video game tournaments" [34]. Other authors define" eSports" as an "area of sport activities in which people develop and train mental or physical abilities in the use of information and communication technologies" [35]. Thus, the term "eSports" sometimes is used as a direct synonymous of digital "sport", but they are not the same. Maybe this confusion is because there are concepts, like 'sport gaming,' 'virtual sports,' and 'exergaming', that are being used to describe the digitalization of playful activities in different ways [35].

The eSports are considered as a "sedentary activity" (or with a low level of physical activity) to be considered an "sport" [36]. And, in the philosophy of sport literature there seems to be 'a solid point of agreement in that the physical skill is a necessary component of all sports [37]. But among the eSports there are games which require physical skill and games which do not [38]. Some authors claims that eSports "require the learning and performance of motor skills and that embodiment within a virtual environment may be considered playful or even athletic" [39]. So, some eSports can be utilized for the development of motor skills, but maybe or not be implies physical exercise [40], as we can observe in examples of eSports with official competition leagues like Counter Strike, WOW (World of Warcraft), League of Legends or FIFA [40].

Although, certain types of eSports cannot be left out of the category of sports, there is not a common criterion about to including eSports into educational contexts [41]. The authors argue that although some eSports can be considered games because it implies the learning of motor skills [39], however, do not concluded that these skills should be taught in physical education programs. They argue that the embodied interaction and visibility of movement behavior can useful to learn about the movement and physical education [39].

\section{Related Projects for Physical Exercise}

There are several research projects related to gamification, education and PE. In Table II we related some of the last relevant European Projects. Among the Spanish related projects, we note the project "Play the Game: gamification and healthy habits in physical education". Hernando et al (2015) [42] have studied the impact of the gamification as learning strategy in PE subject at school. The study has been designed as a didactic unit named "Play the game" where students of three secondary schools has to achieve a healthy cardiac frequency in their physical activity through different challenges, levels, points, leaderboards and badges. Therefore, Play the game has innovative elements, such as personalization, cooperation, emotions, technologies and a combination of formal and informal contexts. The results of Play 
TABLE II. EuropeAn Projects For PE

\section{Description}

Uses wearable technologies and games to encourage healthy lifestyles amongst teenagers [20] shows a case study on the use of Gamification strategies and wearable lifestyle technologies for personal health management, in the framework of the European Project PEGASO. This author describes the results of two-year project exploring the potential of various lifestyle tracking and health monitoring equipment and the impact on the health parameters and well-being. The data captured and visualized by the mobile applications linked to these lifestyle technologies illustrates how gamification and enabling technologies have evolved in support of pervasive personal health management.

URL: http://www.pegaso4f4.eu/

The main goal of DOREMI project is the "active ageing" based on three keys: healthy eating, active lifestyle and social interaction. The decline of cognitive ability is strongly related to lifestyle, as well as social engagement, cognitive stimulation, nutrition and physical activity. DOREMI is focused on social inclusion with the help of cognitive games and the development of a social and gamified environment.

URL: http://www.doremi-fp7.eu/project

The project is named "Breaking Educational Barriers with Contextualized, Pervasive and Gameful Learnin". The 'anytime anywhere' learning concept is developing through pervasive, context-aware and gamified techniques and technologies, framed under the Problem-Based Learning approach. The project will create a platform as ubiquitous solution based on context aware systems, procedural content generation, pedagogy-driven gamification, learning analytics and cloud technology.

URL: http://beaconing.eu/

The project "Gamification of Prosocial Learning for Increased Youth Inclusion and Academic Achievement" is founded on the hypothesis that children at risk of social exclusion, lacking empathy and showing high levels of aggressive or anti-social behaviors, should benefit from digital games tailored to teach prosocial skills (the ability to identify the benefits of cooperation, recognize the emotions and needs of others and express trustworthiness) that can help them achieve academically, appreciate team work and recognize the value of understanding other people's needs. The gamification of prosocial learning will be driven by a set of well-defined prosocial learning objectives that are designed for the development of specific prosocial skills, in terms of prosocial theory, gameplay and game mechanics. Moreover, ProsocialLearn will create a new ecosystem through a new market for digital games, designed to support learning and development of prosocial skills, and offering games developers scientifically proven prosocial game elements for development digital games. An application programming interface (API), ProsocialAPI, will allow developers to integrate functions into games including visual sensing, identification of prosocial signals from in-game actions, personalized adaptation of game elements, player profiles, game mechanics and expressive virtual characters, and support for data collection with protection of personal data. URL: http://prosociallearn.eu/

The main goal of this project is to create an ecosystem of tools and apps to key agents of the sport sector. As Google does with its platform but with the sport as the soul, the core of LEGEND platform is Search but then it provides with dozens of tools. With this tool, public (local government, Universities or Schools) and private (sport facilities, individuals, federations, associations, etc.) managers from all around the world can send real time alerts, manage the classifications in an easy way, generate automatic calendars, publish the rules and news, define roles as referees or team managers and many more features to come. Also they have developed mobile apps for following the league but also the users can organize their friendly matches, comment on them before and after the match, check the results of their friends and to share them in other social networks. So, to motivate people to report the results, the project added an algorithm to calculate their skill level of every sport and also added gamification technics to the app so users can get badges depending on their results. Finally, users can track and check all their stats and historical results.

URL: https://ec.europa.eu/easme/en/sme/5462/legend-sport-goes-viral

the game show the potential of gamification as an emergent learning strategy in PE because increase the motivation and promote the healthy habits in the students.

Other relevant project on gamification in PE is "ExpandeEF" or Expanded Physical Education, work developed by Lucía Quintero (2017) [43]. ExpandeEF was applied during one academic course with students of the second year in a high school of Tenerife (Canary Islands, Spain). Quintero (2017) used not only gamification strategies to design the experience, but emergent didactic methodologies such as mobile learning, flipped classroom or service-learning was applied (Fig. 1).
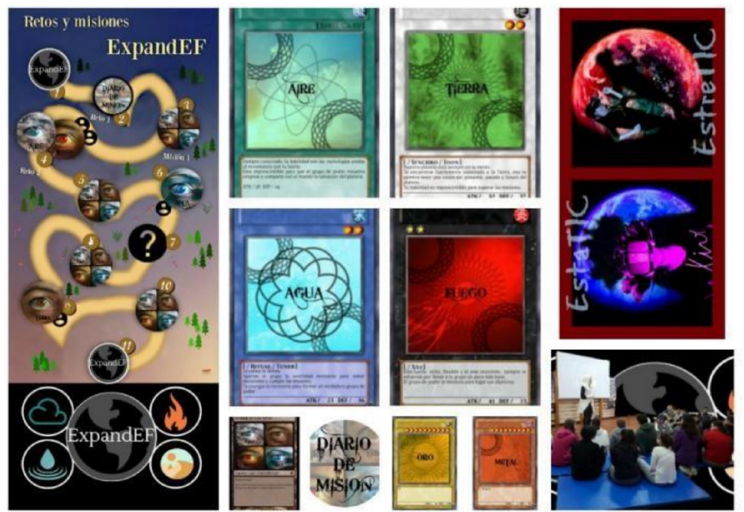

Fig. 1. ExpandeEF project. Source: http://bit.ly/2FNItIx
Also, several related projects have been developed by our research group, such as:

- VIDEM (Developing healthy habits and physical education through active educational games for hospitalized children and adolescents) funded by the Ministry of Science and Innovation, Ref. EDU 2010-10010, had the main goal of developing healthy habits through motor games and active video games in hospital classrooms. Among the objectives of the project, there are: a) Designing a model of educational intervention through physical exercise and ICT. The exercise is the transversal educational strategy, related attitudes and communicative values for integration of minors; b) Evaluating the influence of physical activity with learning games and motor play in learning healthy habits. Besides, training interventions and effectiveness of game models and tools applied are valued. In this context, it has been made and validated an integrated educational program formed by motor games and active videogames for the development of healthy lifestyles at a primary school [32]. URL: http://videm.es/

- SALUD-in (Platform for Interactive Virtual Rehabilitation with Physical Social Games for Health and Techniques of Natural Interaction) Ref PROID20100218, funded by the Canarian Agency for Research, Innovation and Information Society. This interactive platform, aimed at hospitalized children, allow the virtual-based rehabilitation based on physical social games for health and natural interaction techniques. It is based on multiplayer games, with games designed for physical and cognitive rehabilitation, a motion 
capture system and biomedical data based on a low cost system (Kinect sensor and wearables devices). In this project TANGO:H (Tangible Goals platform) was created (Fig. 2). TANGO:H is a platform for hospitalized children with functional diversity developed by the Technological and Renewable Energy Institute (ITER) and the Interaction, Technology and Education Research Group (i-TED) ) of the University of La Laguna. Further it comprises a clinical management system and remote monitoring of rehabilitation exercises and medical records of patients. URL: http://saludin.es/
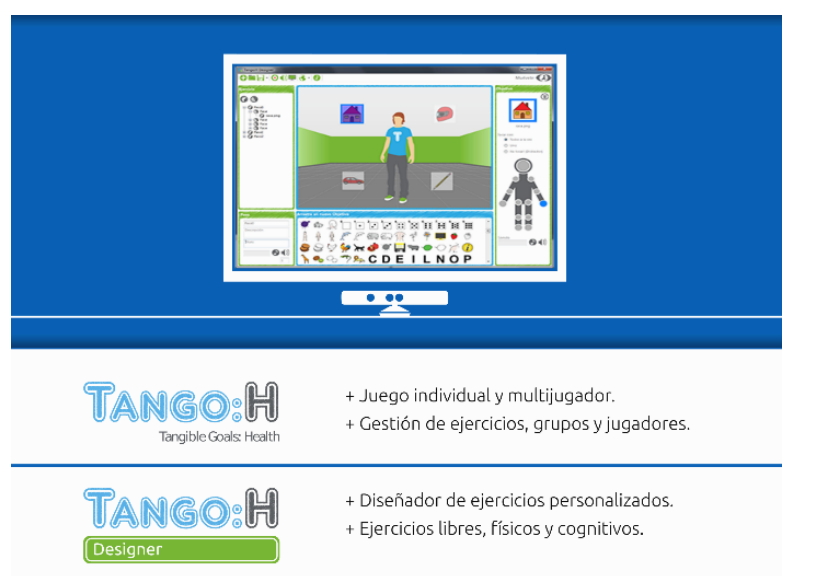

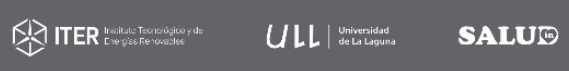

Fig. 2. TANGO:H allow the design of personalized physical games in individual and collaborative modes. URL: http://tangoh.iter.es

- PROVITAO (Active videogames program for Outpatient Treatment of Obesity). The PROVITAO Ref OBE05 project, funded by the CajaCanarias Foundation (2014-2017), aims to support the treatment of obesity at early ages, contributing to improving the state health patients and preventing future disorders in adulthood [44]. It has a model of educational intervention designed for education in healthy habits, with an exercise program, motor games and commercial and own active video games, created in the research group, such as TANGO:H. The whole program is «gamified», in order to motivate and to achieve the engagement of children during the intervention in schools and home (one school year) (Fig. 3). URL: http://provitao.webs.ull.es

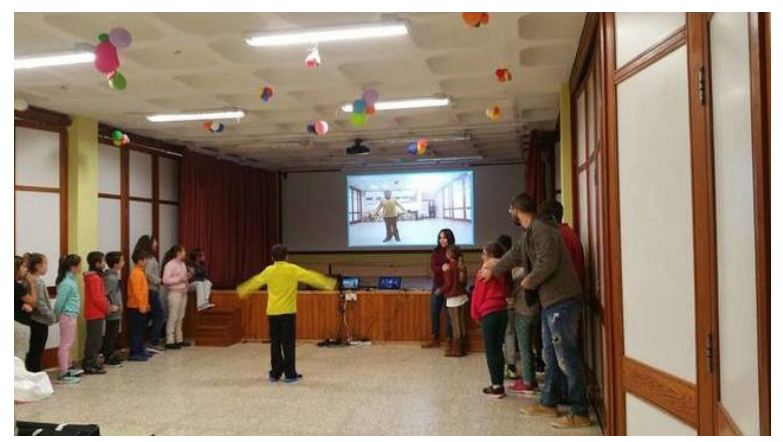

Fig. 3. Children using TANGO:H in the school under the PROVITAO project.

Finally, some example of the last gamified platforms or active games to develop healthy habits and can be used in PE are:

- SuperBetter: This platform increases resilience - the ability to stay strong, motivated and optimistic even in the face of difficult obstacles, making more capable of getting through any tough situation. URL: https://www.superbetter.com/
- Zombies, Run!: is a mobile game for running in which players has to run away from zombies. Then, while players run, stories are narrated, random sprinting to avoid zombies are launched. Players can collect items and be punctuated in personal music playlists. URL: https://zombiesrungame.com/

- Fitocracy: In this app, users work on exercise goals in group/ community, and, also, can have a personal coach to keep motivated in fitness and nutrition. URL: https://www.fitocracy.com/

- VirZoom: this technology combines Virtual Reality (FR) and Fitness Technology. VirZOOM is a static bicycle connected to VR games. For example, the user can live different virtual experiences: power a horse in a race, a tank in battle, a fire-breathing dragon through mountains. URL: http://virzoom.com/

\section{Trends in GAmification and Games For PE}

\section{A. Personalization}

People have different ways to get fun. So, the research has identified different player types and motivations to play. Bartle (1996) [45] identified four player types: killer, achiever, socializer, and explorer. Regarding the motivations, Lazzaro (2004) [46] detected four motivational factors for playing games: hard fun, easy fun, altered state and people factor, and Yee (2006) [47] identified three main motivation components: achievement, social and immersion. So, the student model must represent the way people play, and the types of players. The personalization of game elements in the system [48] should take into account the forms of adaptation proposed by Kobsa et al. (1999) [49]: to user data, to usage data and to environment data. Besides, a typology of engaged behaviors to determine if a player is engaged or not has been proposed by Bouvier et al. (2013) [50]. Some research can help to understand the influence of environment data. For example, Cheng (2011) [51] tried to find the good moments to play at work.

Therefore, in gamification it is important to know how to motivate a particular and different person at the right moment using different types of motivations [52]. Thus, it is possible uses gamification strategies based on intrinsic motivation (inherent in the person, taken for its own sake or interest, for example, status, power, access to certain skills, or to contribute to a common good) or in extrinsic motivation (outside the person, made for reward or feedback). Social strategies can be used to, for example to compete, to collaborate or to compare achievements. In social games, there are collective mechanical equipment (projects, group scores, etc.) and other mechanical applied to the individual (motivation, positive reinforcement, etc.) [53].

Adaptation and personalization are concepts closely related and similar, which have a mutual goal: to offer a closer user experience by offering content close to the user, personalized to your interests and looking for increasing fidelity and satisfaction [53]. To perform this adaptation / personalization, the basic elements are: to define the user profile, to define the content and functionality that you want to adapt, and to define the interface elements that allow this adaptation / personalization. Personalization allows the adaptation of system through different techniques, such as content filtering or rulebased filtering, to infer the user's needs and preferences [54]. For personalization / adaptation of a gamified system, we must think about what are the features that make the system fun and if the system can work with or without these gamified features. We must also think about how these features relate to gamified different user profiles. Moreover, we must also consider whether the system can work independently to gamification without affecting the core functionality, which in our case is learning. For example, a leaderboard can be activated for the most competitive users, while not for others like introspective or special needs users. For the adaptation / personalization experience, the 
gamification engine must decide when and how specific and general features will be activated, taking into account: a) the student model (consisting of the user profile or static information and user history or dynamic information, and b) contextual information.

The static part of the student model or profile contains data such as age, gender, administrative information, learning style, type of player and preferences. Identifying the type and player preferences will increase the student motivation. The dynamics of the model student or history contains information of student interaction with the learning system and the state of their learning. However, a gamified system must also incorporate the trace of student interaction with the system for activation or deactivation of the functionality of gamification to increase the degree of engagement. Moreover, contextual information is essential in a gamification engine. The students can perform the activities from school, work or in their free time, in the classroom with their peers and with the teacher, or remotely. Student can also do the activities from a tablet, a mobile device, a laptop or desktop computer. All these contextual characteristics affect the gamified experience and the gamification engine must be able to adapt the features to different contexts. For example, if the activity is carried out in the classroom with teacher assistance, the chat cannot be very useful.

According to Gadiyar (2014) [55] "many gamification initiatives use points, badges and leaderboards as a way to motivate and incent participants to alter their behavior and use analytics to measure and monitor users' actions and social components to increase the user motivation", but, most of them fail to keep the user involved over the long term. The proposed solution for this problem is the personalization of the entire gamification process.

Gamification techniques should try to understand users, their personality, feelings, behaviors and actions. Big data [56], behavioral insights and elements of psychology can be used in gamification to provide a better end-user experience. Thus, in a gamification experience, every feedback, message or response should relate to user characteristics and situation properly. Typical gamification approaches, includes PBL, Levels, Feedback, Reward and Recognition techniques. The social gamification includes social media, communities, Web 2.0 elements, and big data analytics. Next generation of gamification systems, includes the elements for a personalized and contextual experience, such as: behavior-based frameworks, mental models, neuroscience and big data analytics.

\section{B. Technology for Gamification and Games for PE}

Technology plays a central role in the lives of today's children and young people. So, the use of new technologies, apps and devices into schools, could offer more engaging physical activities and healthier lives to students. Technology should be the core of engagement strategies in PE.

Lister et al (2014) [57] establish that apps "represent a promising opportunity for getting people active and have received considerable attention but this has been at the expense of in-depth analysis of effectiveness" and if the applications are not developed properly, "they will end up in a common technology cycle of hype with the users' feelings of failure and frustration on technology". To promote positive and active user experience in apps, many apps uses gamification, but they only use the most convenient game elements and did not use the full potential of gamification to create a success gaming experience. So, Lister et al (2014) [57] have conducted an analysis of 132 most popular apps in markets and seems to agree with this criticism. Moreover, the authors studied if the apps addressed correctly the motivational components to produce a behavior. They found the apps ignore the individual ability to perform the behavior, being this the main issue to achieve long-term behavioral change. So, digital rewards like badges or points may not produce a long-term behavioral change. We believe that apps have potential in physical education, but the design of these apps needs put attention in to achieve a sustained change in behavior.

According to a report on active life style in young people, it is found that "today's children and adolescents live sedentary lives full of computers, video games and television" [58]. But, certain technology (i.e. wearables, smartphones) that can encourage children to perform outdoor exercise. In this sense, some organizations like Youth Sports Trust, highlighting "the need to include wearable technology and gamification in physical education classes in schools" [59]. Furthermore, they said "in order to get children active from a young age, a more holistic approach to PE is needed, one which integrates technology and the delivery of a seamless, intuitive and digitally enhanced form of physical activity" [58]. Therefore, smart textiles can be introduced in the schools, as PE uniforms, and can take an important role in PE. For example, there are biosignal-monitoring underlayers produced by Athos, which read muscle effort, heart and breathing rates, analyses this information and push recommendations through mobile devices [58].

But tracked data on the activities and statistical information cannot be enough to transform this data into knowledge, skills, attitudes and behaviors [59], motivating and enhancing physical activity. Coaching support in physical activity can be an important key of success in PE. Moreover, school PE teachers will need skills and resources to offer a diverse set of PE activities focused on health, fitness and emotional wellbeing, and supported by technologies. Digital literacy should start at early ages and PE teachers must be put attention at this area. To use effectively technologies teachers requires a specific knowledge, but most primary school teachers tend to be generalists. And, to integrate the technology with the PE in a transparent and intuitive way it is needed to have a holistic approach.

\section{CONCLUSIONS}

In this paper we presented a review about different studies on games and gamification applied to physical exercise, specially focused on the promotion healthy habits. We also present a review about the concept of "eSport" and its relationship with physical exercise and some considerations to be include in physical education programs. We found that many studies on active games or gamified physical exercise has been focused on energy expenditure and motivation.

Although, we found several studies and related project about how to use interactive technologies to promote healthy habits, most of games and gamified programs fail to keep the user involved over the long term. So, we believe that providing a more personalized experience can solve the problem of the engagement in long term. Personalization and emerging technologies (big data, wearables, smart technologies, etc.) based games and gamification for physical activity promising opportunity for getting people active.

Finally, we note that active videogames and gamification can be used in educational programs to increase the motivation of children and adolescents in physical exercise. In this sense, the nursing profession can play a fundamental role in health education. So, the educational programs to promote physical exercise and healthy habits should be designed and developed from the Primary Health Attention Centers and, also, in schools. And, the introduction of gamification into these educational programs (i.e. PROVITAO), can improve the quality of life of children who suffer from childhood obesity thanks to the acquisition of healthy habits.

\section{ACKNOWLEDGMENT}

This work has been supported partially by Fundación Caja Canarias, Project PROVITAO OBE05. 
REFERENCES

[1] Pearce, M. et al. (2011), "Who children spend time with after school: associations with objectively recorded indoor and outdoor physical activity", international journal of behavioral nutrition and Physical Activity, 11:45 (2011).

[2] Cook, W. (2013) Training Today: 5 Gamification Pitfalls. Training Magazine. Retrieved from: http://www.trainingmag.com/content/trainingtoday-5-gamification-pitfall

[3] Schell J. (2008). The Art of Game Design: A book of lenses. Taylor \& Francis US.

[4] Zagal, J., Mateas, M., Fernandez-Vara, C., Hochhalter, B. \& Lichti, N. (2005) «Towards an Ontological Language for Game Analysis». In Proceedings of the Digital Interactive Games Research Association Conference (DiGRA 2005), Vancouver B.C.

[5] Zichermann G. \& Cunningham C. (2011). Gamification by Design: Implementing game mechanics in web and mobile apps. O'Reilly Media, Inc.

[6] Simões J., Díaz Redondo R. \& Fernández Vilas A. (2012). A social gamification framework for a K-6 learning platform, Computers in Human Behavior.

[7] Werbach, K. (2012). For the Win: How Game Thinking Can Revolutionize Your Business. Wharton: Wharton Digital Press.

[8] Nacke, L. E., \& Deterding, S. (2017). The maturing of gamification research. Computers in Human Behavior, 71, 450-454.

[9] Mora, A., Riera, D., Gonzalez, C., \& Arnedo-Moreno, J. (2015, September). A literature review of gamification design frameworks. In Games and virtual worlds for serious applications (VS-Games), 2015 7th international conference on (pp. 1-8). IEEE

[10] Papastergiou, M. (2009). Exploring the potential of computer and video games for health and physical education: A literature review. Computers \& Education, 53(3), 603-622.

[11] Sánchez López AM, Aguilar Cordero MJ, González Jiménez E, Padilla López CA, Álvarez Ferre J \& Ocete Hita E. (2011). La Obesidad como factor pronóstico de la falta de motivación en el niño y en el adolescente. X Congreso Nacional de la SEEDO. Revista Española de la Obesidad. 9(2), 99.

[12] Tan B, Aziz AR, Chua K, \& Teh KC. (2002). Aerobic demands of the dance simulation game. Int J Sports Med. 23(2), 125-129.

[13] Cantallops Ramón J, Ponseti Verdaguer FJ, Vidal Conti J, Borràs Rotger PA \& Palou Sampol P. (2012). Adolescencia, sedentarismo y sobrepeso: análisis en función de variables sociopersonales de los padres y del tipo de deporte practicado por los hijos. Retos. Nuevas tendencias en Educación Física, Deporte y Recreación. 21, 5-8

[14] Borràs Rotger PA, Vidal Conti J \& Ponseti Verdaguer X. (2008). Escuelas promotoras de salud; intervenciones y estrategias para incrementar el nivel de actividad física: revisión y recomendaciones. Libro de ponencias de la IV Congreso Internacional y XXV Nacional de Educación Física. Córdoba: Universidad de Córdoba.

[15] Maddison R, Mhurchu CN, Jull A, Jiang Y, Prapavessis H \& Rodgers A. (2007). Energy expended playing video console games: an opportunity to increase children's physical activity?. Pediatr Exerc Sci. 19(3), 334-343.

[16] Chin A Paw MJ, Jacobs WM, Vaessen EP, Titze S, \& van Mechelen W. (2008). The motivation of children to play an active video game. J Sci Med Spor. 11(2), 163-166.

[17] Lanningham-Foster L, Jensen TB, Foster RC, Redmond AB, Walker BA \& Heinz D. (2006). Energy expenditure of sedentary screen time compared with active screen time for children. Pediatr.. 118(6), 1831-1835.

[18] Lanningham-Foster L, Foster RC , McCrady SK, Jensen TB , Mitre N \& Levine JA. (2009) Activity-promoting videogames and increased energy expenditure. J Pediatr. 154(6), 819-823.

[19] Mellecker RR \& McManus AM. (2008). Energy expenditure and cardiovascular responses to seated and active gaming in children. Arch Pediatr Adolesc Med. 162(9), 886-891.

[20] Maddison R, Mhurchu CN, Jull A, Jiang Y, Prapavessis H \& Rodgers A. (2007). Energy expended playing video console games: an opportunity to increase children's physical activity?. Pediatr Exerc Sci. 19(3), 334-343.

[21] Wetzsleon RJ, Swanson KS \& Pickett K. (2008). Energy expenditure and ground reaction forces of an active video game, Dance Dance Revolution, in healthy weight and overweight children. Med Sci Sports Exerc. 40(5),
S255.

[22] Wortley D. (2015). Gamification and Lifestyle Technologies for Personal Health Management. Europea Conference on Game Based Learning (ECGBL 2015). Steinkjer, Norway 8-9 October 2015.

[23] Hourcade, J.P (2015). Child Computer Interaction. First Edition. Retrieved on 01 July from: http://homepage.cs.uiowa.edu/ hourcade/book/childcomputer-interaction-first-edition.pdf

[24] ExergameFitness.com Retrieved on March 15, 2017 from: http://www. exergamefitness.com/

[25] Magielse, R. and Markopoulos, P. (2009). HeartBeat: an outdoor pervasive game for children. In Proceedings of the SIGCHI Conference on Human Factors in Computing Systems (CHI '09). ACM, New York, NY, USA, 2181-2184.

[26] Lund, H. H., Klitbo, T., \& Jessen, C. (2005). Playware technology for physically activating play. Artificial life and Robotics, 9(4), 165-174.

[27] Sturm, J., Bekker, T., Groenendaal, B., Wesselink, R. and Eggen, B. (2008). Key issues for the successful design of an intelligent, interactive playground. In Proceedings of the 7th international conference on Interaction design and children (IDC '08). ACM, New York, NY, USA, 258-265.

[28] Seitinger, S. (2009). Designing for spatial competence. In Proceedings of the 8th International Conference on Interaction Design and Children (IDC '09). ACM, New York, NY, USA, 123-130.

[29] González C.S. \& Navarro V. (2015). A Structural Theoretical Framework Based on Motor Play to Categorize and Analyze Active Video Games. Games and Culture. 1555412015576613, first published on March 26, 2015 as doi:10.1177/1555412015576613

[30] Padilla N., Collazos C. A., Gutierrez F., Medina N. (2012). Videojuegos educativos: teorías y propuestas para el aprendizaje en grupo. Ciencia e Ingeniería Neogranadina, VOL 22-1, PP 139 - 150, Bogotá.

[31] Collazos C. A., Gonález C.S., Gutierrez F. (2014). Patterns for Monitoring and Evaluating Collaborative Learning Processes in Videogames. LAP Lambert Academic Publishing.

[32] González C.S., Gómez N., Navarro V., Cairós M.,Quirce C., Toledo P., Marrero-Gordillo N. (2016). Learning healthy lifestyles through active videogames, motor games and the gamification of educational activities, Computers in Human Behavior, Volume 55, Part A, February 2016, Pages 529-551, ISSN 0747-5632, http://dx.doi.org/10.1016/j.chb.2015.08.052

[33] Rosell Llorens, M. (2017). eSport Gaming: The Rise of a New Sports Practice. Sport, Ethics and Philosophy, 11(4), 464-476.

[34] Witkowski, E. 2009. Probing the sportiness of eSports. In eSports yearbook 2009, edited by J. Christophers and T. Scholz. Norderstedt: Books on Demand GmbH: 53-56.

[35] Witkowski, E. 2012. On the digital playing field: How we "Do Sport" with networked computer games. Games and Culture 7 (5): 349374.10.1177/1555412012454222

[36] Whalen, S.J. 2013. Cyberathletes' lived experience of video game tournaments. PhD diss., University of Tennessee, MIT Press.

[37] Tamboer, J.W.I. 1992. Sport and motor actions. Journal of the Philosophy of Sport 19: 31-45.10.1080/00948705.1992.9714493

[38] IESF (2018). URL: https://www.ie-sf.org/

[39] Hilvoorde, I. V., \& Pot, N. (2016). Embodiment and fundamental motor skills in eSports. Sport, Ethics and Philosophy, 10(1), 14-27.

[40] Hutchins, B. 2008. Signs of meta-change in second modernity: The growth of e-sport and the World Cyber Games. New Media \& Society 10 (6): 851-869.10.1177/1461444808096248

[41] Wagner, M.G. 2006. On the scientific relevance of eSport. In Proceedings of the 2006 International Conference on Internet Computing and Conference on Computer Game Development, 26-29 June 2006. Las Vegas, NV: CSREA Press: 437-440.

[42] Monguillot, M., González, C., Zurita, C., Almirall, Ll., and Guitert, M. (2015). Play the Game: gamification and healthy habits in physical education. Apunts. Educación Física y Deportes 2015, n. ${ }^{\circ}$ 119, 1.er trimestre (enero-marzo), pp. 71-79. ISSN-1577-4015.

[43] Quintero González, L. E. (2017). La gamificación estática versus dinámica: una experiencia de aula a través de una pedagogía lúdica. ExpandEF. In CIVE'17 (Congreso Internacional de Videojuegos y Educación). Retrieved from: http://bit.ly/2FNItIx

[44] Gómez del Río, N., Martín González, R., González González, C. S., Navarro Adelantado, V., Toledo Delgado, P. A., Navarro Campillo, L., ... 
\& Quirce González, C. (2017). PROVITAO: a research program based on active games for help the abulatory treatment of childhood obesity. In 1st Workshop on Gamification and Games for Learning (GamiLearn'17) Universidad de La Laguna.

[45] Bartle, R. (1996). Hearts, Clubs, Diamonds, Spades: Players Who Suit MUDs. Journal of MUD Research 1, 1.

[46] Lazzaro, N. (2004). Why we play games: 4 keys to more emotion. Retrieved from http://www.xeodesign.com/xeodesign_whyweplaygames. pdf.

[47] Yee, N. (2006). Motivations for play in online games. CyberPsychology \& Behavior 9, 772-775.

[48] Monterrat B., Lavoué E \& George S. (2013). Toward Personalised Gamification for Learning Environments. 4th Workshop on Motivational and Affective Aspects in Technology Enhanced Learning (MATEL 2013).

[49] Kobsa, A., Koenemann, J. \& Pohl, W. (1999). Personalized hypermedia presentation techniques for improving online customer relationships. Technical report No. 66 GMD, German National Research Center for Information Technology, St. Augustin, Germany.

[50] Bouvier, P., Lavoué, É., Sehaba, K. \& George, S. (2013). Identifying Learner's Engagement in Learning Games: a Qualitative Approach based on Learner's Traces of Interaction. 5th International Conference on Computer Supported Education, Aachen, Germany.

[51] Cheng, L., Shami, S., Dugan C., Muller, M., DiMicco, J., Patterson, J., Rohall S., Sempere A. \& Geyer W. (2011). Finding moments of play at work, in: CHI 2011 Workshop (2-5). Vancouver: Canada.

[52] Tondello G., Wehbe R., Nacke L. (2015). Towards a Personalized Playful Digital Wellness Assistant. In proceedings Workshop on Personalization in Serious and Persuasive Games and Gamified Interactions, London, UK, 2015.

[53] González C.S., Toledo P., Muñoz V. (2015). Enhancing the Engagement of Intelligent Tutorial Systems through Personalization of Gamification. International Journal of Engineering Education (IJEE). Vol. 32-1. Pp. 532541.

[54] Uchyigit G. \& Ma M. (2008). Personalization Techniques and Recommender Systems. Series in Machine Perception and Artificial Intelligence. Word Scientific Publishing. Singapure.

[55] Gadiyar A. R. (2014). Gamification 3.0: The Power of Personalization. White paper. Cognizant's Global Technology.

[56] Secades, V. A., and O. Arranz. (2016). Big Data \& eLearning: A Binomial to the Future of the Knowledge Society, International Journal of Interactive Multimedia and Artificial Intelligence 3(6): 29-33. doi: 10.9781/ijimai.2016.364

[57] Lister C, West JH, Cannon B, Sax T, Brodegard D (2014). Just a Fad? Gamification in Health and Fitness Apps. JMIR Serious Games 2014;2(2):e9. URL: http://games.jmir.org/2014/2/e9. DOI: 10.2196/ games. 3413

[58] Future Foundation: Special reports. The Class of 2035. Promoting a brighter and more active future for the youth of tomorrow (2015). URL: http://futurefoundation.net/wp-content/uploads/2015/06/the_class_ of_2035_report.pdf

[59] Bhattacharya, S., and S. Nath. (2016). Intelligent e-Learning Systems: An Educational Paradigm Shift, International Journal of Interactive Multimedia and Artificial Intelligence 4(2): 83-88. doi:10.9781/ ijimai.2016.4212

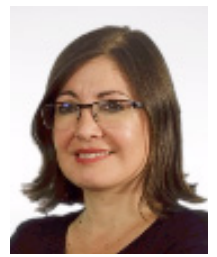

Carina S. González González

Dr. Carina Gonzalez is an Associate Professor at the Department of Computer Engineering and Systems at the University of La Laguna (ULL). PhD in Computer Science, specialized in AI and HCI techniques. Also, she is the head of Interaction, Technology and Education (ITED) research group at Department of Computer Engineering and Systems (ULL). For over 20 years she has focused her expertise in the field of the technologies applied to education and human computer interaction (intelligent tutoring systems, intelligent interfaces, human centered design, UX, serious games, gamification, eLearning, digital culture). She has published widely on these topics.

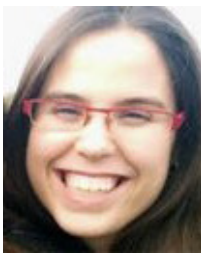

\section{Nazaret Gómez del Río}

Nazaret Gómez del Río is a PhD student in the doctoral Education Program at the University of La Laguna. She is Nurse and has the Master's Degree in Research, Management and Quality in Health Care, with specialization in education. Her main research line is the design and development of gamified educational programs obesity in children. using technologies and active videogames to prevent

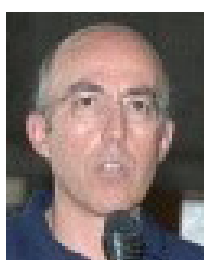

Vicente Navarro Adelantado

Dr. Vicente Navarro Adelantado is an Associate Professor at the Department of Specific Didactics, Plastic and Corporal Expression, University of La Laguna, La Laguna, Spain. PhD in Physical Education, specialized in Teaching and learning in physical education and sports, motor play and active games. He has published widely on these topics 